\title{
Consciências Libertárias, Práticas Colonizadas: Docência e Saúde Através da Pandemia
}

CAIXETA, Izabela Amaral ${ }^{1}$

\section{RESUMO}

Em meio a pandemia do COVID 19, a educação pública no Distrito Federal aposta no retorno remoto às atividades pedagógicas, normalizando as desigualdades sócio raciais quanto ao acesso e à garantia de condições de estudo e trabalho das comunidades escolares, esvaziando também a importância das construções coletivas das ações. Busca-se aqui cartografar, desde um olhar auto etnográfico, as dinâmicas interseccionais das opressões presentes nos processos de saúde e adoecimento que afetam a educação através desse contexto de pandemia racializada. Indaga-se em que medida o enfrentamento ativo ao epistemicídio e ao racismo estrutural como horizontes contra coloniais na educação pública podem atuar como ações de promoção da saúde para além dessa experiência atual. Argumenta-se que a descolonização de consciências e subjetividades, enquanto necessário papel pedagógico, podem trazer lugares de cura e fomentar engajamento coletivo para uma coconstrução de novos mundos.

Educação. Saúde. Contracolonialismo. Epistemicídio. Racismo.

\section{Libertarian consciences, colonized practices: teaching and health areas through the pandemic}

\begin{abstract}
In the midst of the COVID 19 pandemic, public education in the Federal District is committed to the remote return to educational activities, normalizing socialracial inequalities in terms of access and the guarantee of study and work conditions for school communities, also emptying the importance of collective constructions of actions. The aim here is to map, from a self-ethnographic perspective, the intersectional dynamics of oppression present in the health and illness processes that affect education through this context of a racialized pandemic. The question is to what extent active confrontation with epistemicide and structural racism as horizons against colonialism in public education can act as actions to promote health beyond this current experience. It is argued that decolonization of consciences and subjectivities, while necessary pedagogical role, can bring places of healing and foster collective engagement for a coconstruction of new worlds.
\end{abstract}

\footnotetext{
${ }^{1}$ Mestranda em Políticas Públicas em Saúde pela Fiocruz Brasília (MPPPS). Professora da rede pública de ensino do Distrito Federal (Secretaria de Educação do DF). E-mail: izabelacaixeta@gmail.com. Lattes: http://lattes.cnpq.br/3462073497927256. Orcid: https://orcid.org/0000-0003-2103-187X.
}

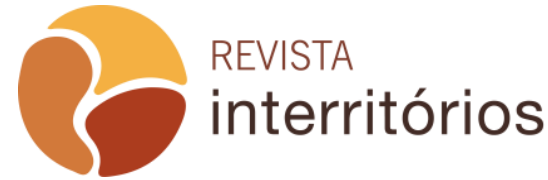


Education. Health. Intersectionality. Counter-colonialism. Epistemicide.

\section{Conciencia libertaria, prácticas colonizadas: enseñanza y salud a través de la pandemia}

\section{RESUMEN}

En medio de la pandemia de COVID 19, la educación pública en el Distrito Federal apuesta por el retorno remoto a las actividades pedagógicas, normalizando las desigualdades socio-raciales en términos de acceso y garantía de estudio y condiciones de trabajo para las comunidades escolares, también vaciando la importancia de construcción colectiva de acciones. El objetivo aquí es mapear, desde una perspectiva auto-etnográfica, la dinámica interseccional de la opresión presente en los procesos de salud y enfermedad que afectan la educación a través de este contexto de pandemia racializada. cómo los horizontes anticoloniales en la educación pública pueden actuar como acciones de promoción de la salud más allá de esta experiencia actual. Se argumenta que la descolonización de las conciencias y las subjetividades, como un papel pedagógico necesario, puede traer lugares de curación y alentar el compromiso colectivo para la co-construcción de nuevos mundos.

Educación. Salud. contra-colonialismo. Epistemicida. Racismo.

\section{Coscienze libertarie, pratiche colonizzate: insegnamento e salute attraverso la pandemia}

\section{RIASSUNTO}

Nella pandemia di COVID 19, l'istruzione pubblica nel Distretto Federale punta sul ritorno remoto alle attività pedagogiche, normalizzando le disparità sociorazziali in termini di accesso e garanzia di studio e condizioni di lavoro per le comunità scolastiche, svuotando anche l'importanza di costruzione collettiva di azioni. L'obiettivo qui è quello di mappare, da una prospettiva autoetnografica, le dinamiche intersezionali dell'oppressione presente nei processi di salute e malattia che influenzano l'educazione attraverso questo contesto di pandemia razziale e indaga il grado di confronto attivo con epistemicida e razzismo strutturale come gli orizzonti anticoloniali nell'istruzione pubblica possono agire come azioni di promozione della salute oltre questa esperienza attuale. Si sostiene che la decolonizzazione di coscienze e soggettività, in quanto ruolo pedagogico necessario, può portare luoghi di guarigione e favorire l'impegno collettivo per la co-costruzione di nuovi mondi.

Istruzione. Salute. Contro-colonialismo. Epistemicide. Razzismo.

\section{INTRODUÇÃO}


No presente trabalho o objetivo é refletir de que forma a educação pública, informada por uma agenda contra-colonial ${ }^{2}$ pode auxiliar na construção de relações pedagógicas que fomentem saúde em seu conceito ampliado. Considerando as estruturas coloniais racistas e sexistas presentes na sociedade, esgarçadas no atual fenômeno de pandemia global e reproduzidas cotidianamente na escola, a proposta é compreender como a ação coletiva e comunitária, ao buscar o enfrentamento ativo dessas estruturas desiguais que determinam socialmente a saúde, pode contribuir ao enfrentar o epistemicídio na educação (RIBEIRO, 2017), agir contra os silenciamentos persistentes e a valorizar as diferentes pluriexistências (NJERI, 2019).

Vivemos hoje uma grave crise política que põe em xeque as fragilidades constitucionais que asseguram a saúde como um direito, bem como a educação. Em meio à pandemia do COVID 19, assistimos aos países ao norte do globo terem seu selo de qualidade em saúde posto em jogo. Na améfrika ladina (GONZALEZ, 1979) onde países como Peru, México e Brasil passam por grandes desafios em suas gestões de crises, tornamo-nos o novo epicentro mundial da pandemia. Até o momento, final de junho, já são mais de 55 mil óbitos pelo vírus só no Brasil. Seguimos sem uma política efetiva de saúde e segurança pública em seu enfrentamento e sofremos as consequências da falsa dicotomia entre o colapso econômico e a preservação da vida, tensionada pelos governos burgueses e suas agendas neoliberais.

Apesar da proposital subnotificação ${ }^{3}$ e omissão estatística de informações a respeito do vírus e sua variável racial, sabe-se que as pessoas mais afetadas pelos seus efeitos sociais são pessoas negras, indígenas, pobres e periféricas (CTC/PUC-RIO, 2020). E não só no Brasil país com a maior população negra fora do continente africano. Isso acontece dadas as condições históricas que 0 racismo estrutural impele às vidas consideradas menos humanas, visivelmente percebidas nos baixos desempenhos dos indicadores de saúde da população negra (GOES; RAMOS; FERREIRA, 2020) e que refletem de forma substancial

\footnotetext{
${ }^{2}$ A noção de contra-colonialidade é compreendida aqui como um conjunto de ações e ideias que se colocam contra a hegemonia colonial econômica, política, espiritual, social exercida pelos países do norte do globo, de capitalismo central contra nossos territórios existenciais amefrikanos ladinos (GONZALEZ 1979) de economia dependente. São ações antirracistas, anticapitalistas, antissexistas inspiradas nas construções afro diaspóricas, ancestrais e afroperspectivadas (NOGUEIRA, 2010) enquanto posições imprescindíveis para enfrentamento das desigualdades estruturais. Esse movimento de contra-colonialidade é também entendido aqui como um deslocar ao sul global das análises e perspectivas, em detrimento do norte eurocristão, branco, heterossexual, elitista.

${ }^{3}$ Ainda que exista um decreto de $\mathrm{n}^{\circ} 39.024$, de 3 de maio de 2018 que disponha "sobre a inclusão do quesito raça, cor, etnia nos formulários, sistemas de informação, avaliação, monitoramento, coleta de dados, censos, programas e ações no âmbito da Administração Pública do Poder"(BRASIL, 2018, p. 13), ainda são poucos os documentos que padronizam e monitoram dados racializados e gendrados nas bases existentes de saúde e educação públicas.
} 
na educação pública enquanto instituição reprodutora desses valores hegemônicos desiguais, causadores de adoecimentos.

No Distrito Federal, um grande indicador de adoecimento protagonizado pela educação se dá na quantidade de atestado médico por saúde mental de professoras e professores para afastamento do trabalho no serviço público (CONSAD, 2014; SEPLAG 2018). São inúmeras as reportagens midiáticas que denunciam essa realidade, endossando as narrativas morais de culpabilização e responsabilização individual do problema. Problema esse, do adoecimento, que é de âmbito coletivo.

A capital do país foi uma das primeiras a fechar os portões das escolas como estratégia de enfrentamento a transmissão do vírus da COVID 19, em março deste ano. Menos de três meses depois retorna obrigatoriamente as atividades educacionais de forma não-presencial, expondo as contradições de um sistema precarizado, mas que persiste em seguir normalizando as exclusões de quem não tem acesso e condições de estudo e trabalho adequados.

Como garantir saúde no trabalho se o trabalho agora é em casa? Uma categoria com mais de $80 \%$ de mulheres (CARVALHO, 2018), perpassadas por múltiplas jornadas de trabalho, centralização do cuidado e manutenção nãoremunerada do 'lar'. Como podemos cruzar esses dados com as informações de aumento exponencial de violência doméstica e feminicídio no contexto de pandemia? Como dimensionar o amparo à estudantes expostas às condições estruturantes da violência por todo esse período quando sabemos que a escola muitas vezes também é lugar de 'proteção, alimentação, acolhimento e denúncias' de violências que ocorrem em casa?

Através dessa constelação de indagações, a bússola epistemológica que proponho é o horizonte ao sul (RIBEIRO, 2017) das experiências contracoloniais. Mais que ilustrar um cenário de relações dinâmicas localizadas, a noção de cartografia aqui muito se aproxima à da Cartografia Social, enquanto uma ferramenta de resistência (FLORES, 2016). Pensar em dimensões cartográficas e existenciais me parece ser, também, uma busca por registrar e costurar ações transnacionais, trazendo uma possibilidade de compreender a luta contra estruturas opressoras desiguais pelo fortalecimento de um ethos comuntário (MIRANDA, 2020) presentes nas sociedades originárias e afro diaspóricas possíveis de inspirar também as nossas comunidades escolares.

\section{Notas metodológicas de uma escrita posicionada}

Lélia Gonzalez recorreu à categoria "amefricanas", as "herdeiras de uma outra cultura ancestral cuja dinâmica histórica revela a diferença pelo viés das desigualdades raciais" como possibilidade de reflexão epistemológica ,para fazer emergir 
diversas tradições de resistência às relações patriarcais a partir das experiências das mulheres negras e indígenas da América, da América Latina, Caribe e Brasil. (CARDOSO, 2014, p. 984).

Esse trabalho contém parte dos resultados de pesquisa em realização (2018-2020) no âmbito do mestrado profissional de políticas públicas em saúde da Fiocruz Brasília. Para compreender a relação do adoecimento docente com as desigualdades estruturais do racismo e do sexismo, elegi como percurso em processo de campo a autoetnografia (SANTOS, 2017), revisão crítica de literatura e análise de fontes secundárias como documentos, notícias de jornais e mídias virtuais a respeito das temáticas de absenteísmo docente, educação, saúde na escola, racismo estrutural, entre outros temas circundantes.

Como professora negra ${ }^{4}$ de sociologia da rede pública no DF há mais de oito anos e filha de professores também da rede pública, hoje aposentada e aposentado, são muitos os atravessamentos das experiências de adoecimento que compõem essa escrita nesse contexto de pandemia. Pensar em 'submeter' à investigação algumas das questões que me afetam no trabalho e na vida fora dele me fazem questionar essa noção de apartamento em nossa identidade, bem como a delimitação de uma temporalidade que considere a memória, a subjetividade, as mudanças formativas. Em um longo percurso de angústias compartilhadas e circulares, tomada de consciência racial e politização dos espaços, a dimensão coletiva dessas questões me trouxe aqui, haja vista que os nossos passos vêm de longe (WERNECK, 2009).

A autoetnografia, segundo Daniela Versiani (2005), pode ser pensada enquanto "espaços comunicativos e discursivos através dos quais ocorre 0 'encontro de subjetividades', a interação de subjetividades em diálogo" (p. 87), valorizando a experiência de quem pesquisa dentro de seu próprio contexto social. E mais, permite:

O reconhecimento, a descrição e a reflexão sobre a própria prática, neste modelo, o sujeito que interpreta é o mesmo que expressa o significado e é o autor da investigação. Neste sentido, o autor seria convidado a repensar o seu papel de produtor de conhecimento e a sua própria subjetividade, construída interativamente e "circunstanciada por sua singular trajetória intelectual e pessoal. (VERSIANI, 2005, p. 88).

\footnotetext{
${ }^{4} \mathrm{~A}$ tomada de consciência racial é um processo doloroso dado legado de memórias violadas, das sucessivas políticas de embranquecimento, ideologia da mestiçagem e apagamentos ancestrais que nos atravessam na améfrika ladina. Assim sendo muito importante afirmar-me como pessoa negra e não parda, como sou lida muitas vezes. Também destaco que enquanto pessoa negra de pele clara, classe média, servidora pública, a sofisticação do racismo me permite alcançar "privilégios" de uma passabilidade conveniente dado o infeliz, porém muito real, colorimos. Isso é muito sério pois quem está nas estatísticas da filtragem letal do racismo são pessoas pretas, não eu.
}

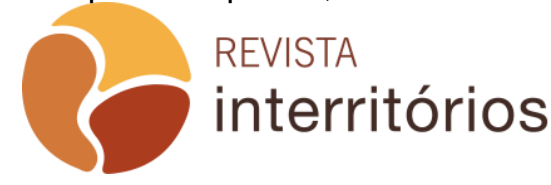


Para melhor refletir e qualificar a discussão sobre adoecimentos no contexto da escola em plena pandemia, para refletir sobre os 'meus pares', sobre a categoria da qual faço parte, ao passo que é um desafio o manejo da (im)parcialidade, existe potencial de um lugar de enunciação diferenciado. Nesse sentido, a autoetnografia emerge como possibilidade em articular minha posição dentro do campo, implicada e comprometida, junto de ferramentas qualitativas disponíveis para debater criticamente de que forma a 'impregnação' do campo pode auxiliar em novas contribuições epistemológicas.

Dentro dessa abordagem de contribuições 'impregnadas', destaco o sentido de 'observadora de dentro', também presente na famosa sociologia de Chicago, como também na 'significação sociológica' do pensamento feminista negro norte-americano (como nos trabalhos de Patricia Hill Collins) e brasileiro (no "lugar de fala", de Djamila Rineiro). Tendo como imprescindível pensar desde o contexto em que se está inserido, considerando que os "conhecimentos são livres porque empíricos e subjetivos' (BANIWA, 2008, p.7) é nesse sentido em que mobilizo o suleamento de uma proposta de auto etnografia aqui aplicada.

A proposta também engloba estratégias cartográficas de mapear os diferentes e possíveis movimentos presentes nessa experiência, incluindo junto das dinâmicas estruturais de opressão a minha própria participação nesse movimento de mobilizar saúde e sofrimentos na escola.

A perspectiva interseccional é entendida como ferramenta imprescindível para analisar as relações de determinação social em saúde (WERNECK, 2016) em contexto de pandemia racializada (CAMPOALEGRE, 2020). Enquanto enfoque teórico-metodológico e político (VIVEIROS, 2013), a interseccionalidade compreende a interação em múltiplos níveis, às vezes simultâneos, das diferentes categorias de discriminação social, ocidentalmente clivadas, como raça, gênero, sexualidades e classe, sendo basilar para analisarmos sistemas e políticas públicas, como a educação e saúde.

Partindo da centralidade racial em nosso contexto de colonização por todo continente americano, invadido por europeus que cometeram genocídios seculares contra os povos originários e lucraram com a violenta escravização africana, acumulando riquezas roubadas ao norte do globo, o conceito de pandemia racializada aqui alinha-se à proposta da professora afrocubana Rosa Campoalegre (2020). No Boletim chamado "La pandemia racializada: Debates desde la Afroepistemología" lançado este ano, a professora e demais autoras destacam como esta proposta de análise da pandemia parte desde um lugar de enunciação dos povos afrodiaspóricos.

Sob a perspectiva necessariamente interseccional, a ideia, segundo Campoalegre (2020) é "recorrer críticamente la situación actual bajo el impacto de la pandemia en las Américas, dejando claro cómo el entrecruzamiento entre 
"raza," género, clase y territorios, profundiza el impacto de COVID-19" (p.5). Nesse sentido, somo-me àquelas que buscam interseccionar reflexões a fim de compreender como a educação pública se insere no aparato colonial reprodutor de desigualdades adoecedoras.

Assim, em tempos de desgaste, sobrecargas e receios compartilhados, torna-se importante pensar em como agir contra essas condições estruturais a fim de se promover saúde ampliada. Considerando que "a promoção da saúde propõe a articulação de saberes técnicos e populares e a mobilização de recursos institucionais e comunitários, públicos e privados para seu enfrentamento" (BUSS, 2000, p.165), proponho aqui um olhar docente desde uma perspectiva da escola pública nesse contexto de busca por saúde em tempos (e para além ) de pandemia.

\section{Racismo e docência: o que essa categoria adoecida pode nos informar?}

enquanto denegação dessa ladinoamefricanidade, o racismo se volta justamente contra aqueles que, do ponto de vista étnico, são os testemunhos vivos da mesma, tentando tirá-los de cena, apagá-los do mapa. (GONZALEZ, 1988, p. 23).

São mais de duas milhões de pessoas que exercem a docência no Brasil atualmente, tanto no setor público (77\%) quanto no privado $(23 \%)$, segundo pesquisa realizada sobre perfil de professoras e professores na educação básica (CARVALHO, 2018). A educação básica é composta por: educação infantil, anos iniciais, anos finais (maior quantidade de profissionais) e ensino médio. De acordo com a pesquisa, a maioria de profissionais concentra-se no sudeste do país. A categoria é composta majoritariamente por mulheres (representam 81\%), fato este que marcará a inflexão no plural da categoria docente no gênero feminino daqui em diante.

Sublinho que, a respeito da autodeterminação étnico-racial nesta pesquisa realizada sobre o perfil, mais de $27 \%$ das duas milhões de pessoas não declararam esse dado. A falta de autodeclaração sobre sua própria raça e cor é comum no Brasil, ainda que hoje a população negra se declare maioria (pessoas pretas e pardas somam mais de 50\% da população). Atribui-se a essa falta de percepção de nossas próprias racialidades, brancos inclusos, ao mito da democracia racial e a ideologia da mestiçagem, muito fortes no país (NASCIMENTO, 1978) e constantemente reproduzidos na escola.

Muitas pessoas na escola aprendem a reproduzir frases como a "cor não importa", "que todos são iguais, todos humanos". Muitas pessoas também dizem saber que não são brancas, mas não se acham retintas o suficiente para se 
entenderem como pessoas negras uma vez que nosso racismo é também epidérmico.

Isso se deve, em grande medida, ao desconhecimento profundo da história dos povos no Brasil, do continente africano e suas diásporas no mundo, dada a forte violência colonial racista que (de)forma subjetividades, fomentando auto ódio e autonegação do ser negro (SOUZA, 1983; FANON, 2008) num país de dominação ideológica da branquitude. Enfatiza-se que:

raça é um conceito relacional, construído e atualizado na modernidade. Apesar da inexistência de diferenças biológicas, raça é um dispositivo político importante na naturalização de violências e desigualdades. A branquitude pode ser definida como um lugar de privilégio nas sociedades constituídas pelo racismo.[...] Refere-se à percepção de si mesmo como universal e dos demais como seres racializados. Branquitude implica em uma autopercepção distorcida, carregada de significados de norma, estética, cultura, etc. (MEDEIROS, 2019)

Essa 'guerra racial' moderna contra todas as populações indígenas e negras na história desse país acaba por ser incorporada nas narrativas institucionais, expostas na centralidade da datação eurocêntrica dos acontecimentos e da folclorização dos povos originários e africanos, bem como sua invisibilidade. Somada às políticas estatais de embranquecimento, controle das imagens pela mídia hegemônica desumanizadora e criminalizadora dos corpos negros (FLAUZINA, 2006), este pode ser um caminho para compreender o porquê de as pessoas quererem parecer menos com o alvo das balas policiais e mais com a elite doriana ${ }^{5}$.

Enquanto perfil étnico-racial da categoria a nível nacional temos $29,3 \%$ de docentes negras, $0,7 \%$ de amarelas, $0,6 \%$ de indígenas e $42 \%$ de pessoas que se declararam brancas, fora os $27 \%$ que não se declararam (CARVALHO, 2018). É válido questionar em que medida o papel da baixa representatividade de pessoas não-brancas, num país de maioria negra, na categoria de professoras e professores pode influenciar no espelhamento, formação e letramento racial na escola.

No DF, de acordo com a Secretaria de Educação- SEDF, a categoria no setor público é composta atualmente por mais de trinta e três mil professoras em regência (total de 33.732 pessoas), sendo vinte cinco mil efetivas e oito mil e quinhentas temporárias (SEDF, 2020). As mulheres representam $72 \%$ do quadro (SEDF, 2018). Não foram encontradas informações a respeito de dados étnico-

\footnotetext{
${ }^{5}$ Referência popularizada da imagem caricata de propagandas de margarinas no brasil que, por muitos anos, representam o farto café da manhã da ideal família tradicional brasileira, uma imagem padrão formada hegemonicamente por pessoas brancas, de preferência loiras, magras, heterossexuais, ricas e jovens.

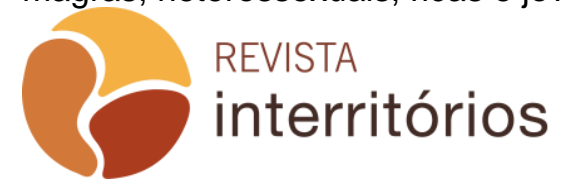


raciais da categoria no DF. Professoras atendem 450 mil estudantes, distribuídas em 683 escolas. Reproduzindo os dados a nível nacional, a maioria das pessoas concentra-se nos anos finais do ensino fundamental, tanto professoras quanto estudantes, sendo também a maioria das escolas destinadas a esse segmento.

Segundo dados do Instituto Nacional de Estudos e Pesquisas Educacionais Anísio Teixeira -INEP (BRASIL, 2019), mais de 50\% de estudantes nas escolas públicas no país são pessoas negras, com maioria do sexo feminino. A taxa de evasão (abandono escolar) é ainda mais alta entre a população negra, em que $33 \%$ de mulheres negras no país não concluíram o ensino médio. $\mathrm{Na}$ Educação de Jovens e Adultos, segmento hoje ameaçado de extinção pelas reformas educacionais, têm no seu perfil maioria de estudantes negras, fora da faixa etária escolar ou com estigma curricular (repetência, transferência, etc).

É histórica a atuação sindical da categoria docente no DF quanto às reivindicações de melhores condições de trabalho. Hoje, diferentemente do restante do país, nós professoras da rede pública de educação básica temos um tempo maior de coordenação pedagógica e, em contrapartida, menos tempo em sala de aula (ROCHA, 2015). A chamada "jornada ampliada" representa uma conquista de valorização do trabalho docente para além da regência, mas ainda é motivo de disputas e dissensos (CRUZ; MEDEIROS, 2017) e segue ameaçada pelos governos desde seu deferimento em 2011.

Comparado às demais professoras do setor público no país, a remuneração salarial no DF é hoje a quinta (5) mais alta, ficando atrás somente das docentes do Maranhão-MA, Mato Grosso do Sul- MS, Tocantins- TO e do Mato Grosso, respectivamente (SANTIAGO, 2019). Outra particularidade da categoria no DF é que é a única no Brasil a criar, em 1997, uma escola de aperfeiçoamento para profissionais da educação que atualmente funciona como subsecretária de formação continuada (EAPE).

A respeito da afirmação de que as professoras no DF formam uma das categorias mais adoecidas do país, consideram-se aqui os dados sobre atestados médicos como a 'mensuração' desse adoecimento. O DF aparece em pesquisa nacional (CONSAD, 2014) como o estado com os piores índices nas frequências de licenças médicas. Segundo a pesquisa, que considerou indicadores de frequência de atestados e duração dos mesmos (CONSAD, 2014), "essas evidências colocam o Estado [DF] em segunda situação mais crítica quanto à evolução dos indicadores" (p.10). O Rio Grande do Sul se destaca como região de maior índice de duração nos atestados.

No que tange as doenças relacionadas ao afastamento do trabalho por motivos de saúde (absenteísmo), "os Transtornos Mentais e Comportamentais como o adoecimento que mais custa aos Estados" (CONSAD, 2014, p. 13) são destaques entre as doenças periciadas no DF. Outro relatório, produzido em 2018 (SEPLAG, 2018), reforça a ideia em âmbito local quando afirma que "a 
SEE/DF sofre grande impacto em relação aos transtornos mentais e comportamentais, apresentando uma proporção bem superior dessas doenças em relação aos demais órgãos do GDF" (SEPLAG, 2018, p7).

É importante destacar que o 'usufruto' do atestado médico (fonte que gera os dados sobre absenteísmo) não é homogêneo entre as diferentes categorias profissionais de uma escola. Por exemplo, as professoras temporárias, as categorias terceirizadas como limpeza, conservação, merenda, entre outras, encontram reais dificuldades de 'acesso, gozo e respaldo' ao direito à saúde (PASSOS; NOGUEIRA, 2018).

Para compreender como a saúde mental conecta-se com os atravessamentos desiguais da sociedade que (de)forma a construção psíquica das pessoas, trago primeiro o conceito ampliado de saúde, formulado em 1986, na importante $8^{\mathrm{a}}$ Conferência Nacional de Saúde, onde consta que saúde abrange o resultado:

das condições de alimentação, habitação, educação, renda, meio ambiente, trabalho, transporte, emprego, lazer, liberdade, acesso e posse da terra e acesso a serviços de saúde. É, assim, antes de tudo, o resultado das formas de organização social da produção, as quais podem gerar grandes desigualdades nos níveis de vida. A saúde não é um conceito abstrato. Define-se no contexto histórico de determinada sociedade e num dado momento de seu desenvolvimento, devendo ser conquistada pela população em suas lutas cotidianas. (Anais da 8 a CNS, 1986). (grifos da autora).

Nesse sentido, a noção de interdependência social para a produção de saúde e adoecimento é indispensável para compreendermos nossa situação atual de contaminação, isolamentos e pandemia racializada. Os chamados determinantes sociais em saúde incluem o racismo e o sexismo "como fatores estruturais produtores da hierarquização social associada a vulnerabilidades em saúde" (WERNECK, 2016, p.540).

É muito presente na literatura sobre adoecimento docente o lugar da escola como espaço de sofrimentos. O papel da instituição colonial moderna que é a escola há muito vem sendo 'denunciado' e segue como importante dimensão para pensarmos em que medida nossas formações e reproduções de valores excludentes contribuem para a produção de adoecimentos dentro e fora da escola. Lá, geralmente, não aprendemos a valorizar o diferente, o fora do 'padrão' hegemônico. Não é "uma preparação para que aprendamos a ouvir essas outras vozes, mas uma preparação para tolerá-las e superá-las na medida em que nos esforcemos por modernizá-las" (BOTELHO, NASCIMENTO, p.80, 2010). 
Os processos de subjetivação, ligados às relações sociais produzidas no contexto de racismo e sexismo estruturais, advém de um legado escravocrata patriarcal capitalista, que é silenciado e negado, contribuindo para uma construção distorcida da noção de si e do outro (SANTOS, 2017) enquanto seres dispensáveis, inimigos. A respeito desses processos de formação racializada das subjetividades, Deborah Medeiros no elucida que:

os brancos, que constituem o grupo dominante, saíram do sistema escravista com uma herança material e simbólica extremamente positiva, fruto da apropriação de quase quatro séculos de trabalho dos negros, e essa negação perpetua suas fantasias meritocráticas, como nos mostram trabalhos recentes sobre o fenômeno da branquitude. Além disso, o Brasil implementou uma política de branqueamento com o objetivo de apagar o negro do ponto de vista biológico. O impacto dessa política é sentido até hoje. A prosperidade dos brancos imigrantes, por exemplo, não se explica somente pelo esforço desse grupo, mas também pela discriminação imposta aos trabalhadores negros. A resistência em lidar com essa realidade se dá porque isso afeta a imagem idealizada pelos brancos sobre seus antepassados. A negação, portanto, é parte do racismo estrutural. (MEDEIROS, 2019).

Muitos trabalhos vêm demonstrando em que medida essas táticas de negação presentes no racismo estrutural afetam as dinâmicas na escola, nas subjetividades de estudantes, crianças a adultos. O sofrimento docente geralmente não é percebido sob essa ótica interseccional.

Nesse cenário de adoecimentos exponenciais, queixas constantes, em tempos de isolamento social devido a pandemia, a categoria de professoras do DF retoma o trabalho obrigatório a distância, na contramão de outras cidades no mundo que vem repensando 0 ano letivo. Sem garantias às condições necessárias de trabalho, nem políticas públicas de saúde para o enfrentamento real do vírus e seus efeitos sociais, são muitas as perguntas que se levantam a respeito de como a saúde (em seu conceito ampliado) se constituirá nesse percurso de aviltamentos e iniquidades.

Como a categoria docente, considerada uma das mais adoecidas do país, vem lidando com essa situação de retorno às aulas a distância, de forma remota? Digo por mim quando afirmo que o cenário não está nada bom. Mas penso que me somo às muitas outras sensações de incerteza, ao julgar pelas inúmeras notas de repúdio sobre a forma como tem ocorrido as aulas remotas pelo país, bem como relato de experiências e reportagens sobre a situação. Saber que não estou só nesse mar de angústias, medos e dores me fortalece de algum modo pois, sendo estrutural essa situação, torna a ação contra-colonial ainda mais importante e urgente.

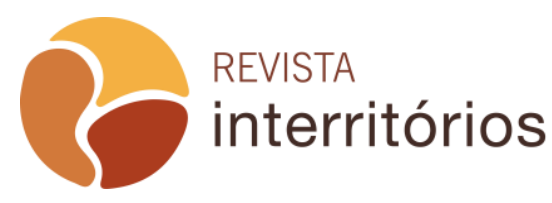




\section{Educação a distância na rede pública: "solução ou migué"}

No dia do retorno às aulas remotas da rede pública de ensino ( 5 de junho, sexta feira) anunciada pelo governo em menos de 48 horas antes, um jornal popular $^{6}$ da capital do país noticiou uma reportagem com a seguinte manchete: "Aula a distância para salvar o ano letivo no DF: solução ou migué? (CARDIM; ALCÂNTRA, 2020). A reportagem não chega a explicar o uso da expressão migué, nem mesmo seu significado. Penso que contaram com o poder comunicacional e transfronteiriço que as gírias carregam. A palavra migué significa basicamente: enrolação, 'conversa mole', papo inconsistente, enganação.

Eu, particularmente, adoro um deboche. Uma zombação explícita carrega consigo o poder político da ironia, de evidenciar "contradições que não se resolvem - ainda que dialeticamente - em totalidades mais amplas: ela[a ironia] tem a ver com a tensão de manter juntas coisas incompatíveis porque todas são necessárias e verdadeiras" (HARAWAY, 2009, p.35) Entre o humor e a seriedade, reflitamos sobre esse deboche.

Uma linha de teoria explicativa da gíria migué faz referência a figura de dom Miguel, irmão do famoso imperador do Brasil, o português Dom Pedro I. O dom Miguel casou com a própria sobrinha no intuito de dar um golpe e assumir o trono em Portugal. Sua fama e reputação de traiçoeiro parecem fazer parte das diversas heranças coloniais ainda presentes nas gramáticas morais em nosso país (NASCIMENTO, 2019).

A reportagem, baseada no Plano Escola em Casa da SEDF, informa sobre as atividades remotas que vão ocorrer basicamente através de duas mídias: a TV aberta e uma parceria público-privada com a plataforma online da empresa multinacional norte-americana Google. As emissoras de TV7 receberam materiais elaborados por um pequeno grupo de professores da secretaria, junto com consultores da rede privada. São elas: 1 - TV Justiça, canal público sem fins lucrativos; 2- TV Gênesis, emissora de programação evangélica, propriedade da

\footnotetext{
${ }^{6}$ Cabe mencionar que o jornal pertence ao presidiário, empresário e político brasileiro Luís Estevão, ex senador da república e ex deputado, condenado em 2006 a mais de 30 anos de prisão.

${ }^{7}$ Destaca-se junto a esse cenário, em âmbito nacional, o assombroso caso da nova empresa IP.TV, financiada por empresários favoráveis ao presidente Bolsonaro e maior fornecedora hoje da maioria dos aplicativos usados na rede estadual pública do país. A empresa está sendo denunciada por propagar discursos criminosos e inapropriados pró-ditadura e uso de armas para um público menor de idade. Para ver melhor a respeito das denúncias, acessar: https://theintercept.com/2020/06/15/app-empresa-tv-bolsonaro-aulas-online-pandemia/
} 
rede Sara Nossa Terra e 3- TV União, de um candidato de partido de centrodireita.

A ideia é passar uma programação educativa unificada que não considerou os currículos trabalhados na maioria das escolas, nem contou com participação da categoria para a sua elaboração. As aulas são transmitidas na TV aberta e nós, docentes, devemos atrelar nossas aulas obrigatoriamente a esse conteúdo produzido.

A segunda plataforma, o google sala de aula, tem também seus desafios. O governo da capital diz que até o final do mês de junho, quando estudantes passariam a ter suas presenças obrigatórias junto às plataformas, a SEDF fornecerá pacote de controle de dados gratuitos para professoras e estudantes. No entanto, nada se sabe sobre qual empresa proverá esse serviço, com que dinheiro será pago ou como isso de fato pode se dar já que até o momento (segunda metade junho) não há nenhuma ação nesse sentido.

O que se sabe é que mais de cento e vinte mil estudantes não têm acesso à internet, que milhares de professoras também não possuem condições materiais (CARLA, 2020) e que a instabilidade e confiabilidade nas tecnologias remotas têm graves limitações.

Essas tensões, capturadas no deboche do questionamento sobre as aulas remotas serem ou não uma enganação (migué) feito pela reportagem do jornal expressa muito bem a desconfiança generalizada às ações da educação pública. As palavras que reinam nas redes sociais entre docentes são "desorganização, desinformação, desespero".

Até o momento, diferentes protocolos foram exigidos e, logo em seguida, suspensos devido às instabilidades da rede de internet e da impossibilidade de concretude em realizar procedimentos que desconsideram por vezes a materialidade da vida. Desde suposição de acesso generalizado às tecnologias, a propostas irresponsáveis de exposição de professoras e estudantes com versões impressas de materiais a serem retirados, às vezes na própria escola, para quem não tem internet, desconsiderando todas as recomendações de isolamento nesse momento tão crítico da pandemia no país.

Existem docentes que tomaram frente ao voluntarismo e se dispuseram a sair de suas casas e gravar vídeo aulas em um estúdio fornecido pela SEDF. Esse movimento de voluntarismo pode ser lido, para além do cunho de caridade cristã muito presente na escola pública, como um reflexo de discursos que romantizam a profissão docente, enquanto um ofício, 'um dom's, uma forma de

\footnotetext{
${ }^{8}$ Essa ideia de "trabalhar por amor" (sem precisar receber melhores salários ou salário algum, nem precisar de instrumentos de trabalho adequados) virou motivo de chacota entre professoras na capital logo após o jornalista Alexandre Garcia , conhecido por suas falas de criminalização da categoria, dizer em agosto de 2014 que ser "professor não é profissão, é missão" (acessar vídeo em https://www.youtube.com/watch?v=iFF0O181-II.
} 
heroísmo, dada as capacidades quase 'inatas' de alguns. Ser "professora youtuber" virou motivo de chacota e apreensão.

Há a figura de docentes que se sentem impelidas a mostrar que estão tentando se adaptar a qualquer custo a essa situação, 'mostrando trabalho', haja vista que é muito comum discursos midiáticos que cobram e culpabilizam docentes quanto ao desempenho da educação, sob a suspeita de arruinar e doutrinar o potencial transformador da sociedade (as crianças e os jovens são o futuro da nação!). Enquanto isso, nas redes sociais, pessoas de classe média declaram sentir falta do papel de "depósito" das escolas por não saberem como lidar com filhas e filhos em casa, junto às inúmeras demandas domésticas e profissionais nessa nova rotina de suspensão das aulas presenciais e isolamento social para algumas pessoas.

O receio das professoras, a auto culpabilização e o agir individualmente ("estou ao menos fazendo a minha parte", como muitas alegam), advém em grande medida da histórica desvalorização da categoria e da centralidade que docentes ganham com as reformas educacionais que visam transformar a educação em mercadoria (ASSUNÇÃO;OLIVEIRA, 2009). Essa intensificação e sobrecarga do trabalho gerada pelas ações de precarização na educação pública produz inúmeros sofrimentos e relaciona-se também ao aumento do afastamento do trabalho por motivos de saúde. Segue também paralela às ações politizadas da categoria que, quando organizada, sofre grande repressão das instituições.

A ideia de professor VA-GA-BUN-DO ${ }^{9}$, criminalizada na vida real, também foi alvo de sátira na TV. Criminalização inclusive com uso de violência policial autorizada pelos 'governos democráticos', como nos casos recentes das greves da educação no DF e no Paraná em que até cães de polícia foram utilizados contra trabalhadoras.

Fala-se também da falta de formação tecnológica da categoria que vem tentando acompanhar lives (transmissões ao vivo de aulas/debates/palestras

\footnotetext{
${ }^{9}$ Alusão ao vocativo desqualificador utilizado pelo personagem do humorista Marcelo Adnet, na paródia global "Vila Militar do Chaves", transmitida no dia 15 de janeiro de 2019. Através do personagem fardado do 'Capitão', dono da Vila, este se refere ao personagem do Professor Girafalles como 'vagabundo'. Com natureza de sátira -política, o episódio fez uma releitura do famoso seriado mexicano A Vila do Chaves, com referências a política atual do país e ao líder carismático da presidência. O Capitão, figura autoritária, desfere o mesmo vocativo para as demais personagens, como a 'fraquejada que o pai deu' a respeito da Chiquinha e seu casaco vermelho, logo criminalizada por ser comunista. Chaves, representante da população em situação de rua, é também marginalizado e criminalizado pelo Capitão. Dona Florinda (mãe 'solteira') e Kiko ("garoto afeminado"), representantes do estereótipo da família desestruturada, por falta de uma figura paterna para impor-Ihes a ordem. E por fim, Professor Girafales, professor que propaga ideologia de gênero desvirtuando as famílias tradicionais, logo também chamado de "VA-GA-BUN-DO".
} 
pela internet que ganharam imensa força em contexto de isolamento) de aulas sobre o assunto, apesar de todas as contradições e inconstâncias desses tempos de medo, mortes e sofrimentos. Contradições, pois, espera-se formação tecnológica para uma categoria de trabalhadoras quando o próprio governo patrão carece de segurança digital, como no icônico caso do diário de classe da rede pública de ensino que foi hackeado ano passado. Esse instrumento normativo de trabalho funciona somente online. Destaca-se que o diário já era preenchido majoritariamente em casa pois muitas escolas não possuem internet nem computadores à disposição das docentes devido a precariedade das condições de trabalho.

Vivemos, nos últimos anos, tendo nossa liberdade de cátedra ameaçada sob a vigilância e perseguição moldada pela 'suspeição doutrinária marxistafreiriana, destruidora das morais e bons costumes', alegadamente presente nas escolas públicas. Principalmente contra professoras das humanas (disciplinas consideradas no currículo como atividades de pensamento crítico). Projetos como Escola sem Partido, a retirada da palavra de gênero dos currículos norteadores, proposta de comemoração do dia da família cristã, dos vários casos denunciados de racismo religioso, das perseguições da autonomia docente, etc $^{10}$.

Professoras de sociologia e filosofia foram recentemente consideradas desperdícios de dinheiro público e inimigas da pátria pelo ex-Ministro da Educação (e possível foragido da lei) Abraham Weintraub. O mesmo que, antes de sua saída ligeira do país e do alto posto da educação que ocupava, revogou a portaria de 2016 que estabelecia a política de cotas para negros, indígenas e pessoas com deficiência em cursos de pós-graduação nas universidades federais (ato posteriormente revogado). Com falas ressentidas e expressões de ódio registradas contra populações indígenas e negras, o ex-ministro colecionou ataques e ilustra muito bem como a educação no país é herança colonial de importância estratégica e em constantes disputas.

Se não fossem os movimento estudantis periféricos, por exemplo, o Exame Nacional do Ensino Médio, o ENEM, teria continuado com data marcada antes da pandemia, alargando ainda mais o fosso desigual entre a educação pública e privada no que tange o acesso ao ensino superior, já que as aulas da rede pública estão suspensas presencialmente por quase todo o brasil.

\footnotetext{
${ }^{10}$ Sobre esse assunto, destaco o recente caso em escola militar do DF, onde um major professor de geografia, em sua aula virtual, criticou a arbitrariedade de tratamento que policiais militares deram para manifestantes pacíficos antirracistas nas ruas e para manifestantes prófascismo. Ele foi exposto na mídia, denunciado e afastado de suas atividades. Para saber melhor as importantes diferenças entre escolas militares, as escolas militarizadas e as escolas cívico-militares, destaco o trabalho da professora doutora Catarina de Almeida Santos e do Observatório da Militarização das Escolas do DF , criado no âmbito da Câmara Legislativa dado o contexto de denúncias de assédio moral, assédio sexual, abuso de autoridade, entre outras, que vem ocorrendo desde o início da militarização das escolas no DF.
}

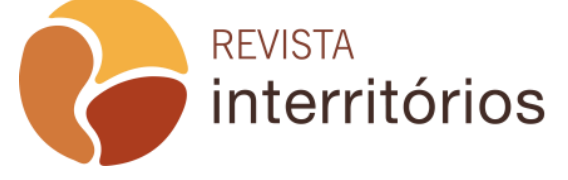


Longe de afirmar que a 'solução' das aulas remotas deva ser prontamente descartada ou, ainda, que essa burocratização das atividades virtuais e aulas na TV são "só para inglês ver", acredito que os problemas estruturais da educação marcham antes desse contexto de pandemia e certamente não serão resolvidos exatamente nesse momento, de forma pontual ou isolada. Essa experiência inédita para todas as pessoas envolvidas ainda renderá muitas questões.

Até o momento, vivemos um período de confusão e falta de comunicação entre trabalhadoras na educação. São pouquíssimas as ações coletivas nas escolas e cada vez mais relatos de adoecimentos. O meu 'farol' nessa tempestade tem sido o compromisso da coerência com um ensino de qualidade, que tenha como centro as/os estudantes e as diferentes possibilidades de vivermos. Atribuo esse suleamento do meu engajo, sobremaneira, ao que venho aprendendo com o movimento negro educador (GOMES, 2017). Cada vez que conheço mais sobre nossos saberes emancipatórios, construídos inclusive em solo brasileiro, fortaleço meu senso de coletividade frente a responsabilidade que é ser espelho na escola.

Talvez por que essa experiência de encontrar nas literaturas marginalizadas um espaço de diálogo, de entendimentos para além da história única e linear que nos impõem, pois é também uma forma de cura. De descortinar as janelas da visão colonizada. É profundamente doloroso se enxergar dentro de um coletivo em guerra. Mas também é fortalecedor encontrar narrativas que agregam, fazem sentido para a nossa realidade ao sul global, explicam de outras formas que não dogmáticas, mas sim generosas. Generosas, pois, fecundam muitos universos. E é muito sobre enfrentar essas táticas que querem eliminar o diferente que me parece ser tarefa pedagógica necessária para uma educação 'saudável' e contra colonial.

\section{Pandemia racializada: analisando o lugar da educação na construção de novos horizontes}

no se puede asumir una posición contrahegemónica que no implique la actitud antirracista, dado que el racismo es una de las desigualdades sociales más profundas y persistente". (CAMPOALEGRE, 2017, p. 34).

Para melhor compreendermos a pandemia radicalizada, consideremos 0 conjunto das opressões estruturais de raça, gênero, territórios, idade em nosso contexto brasileiro para situar como as populações negras e indígenas seguem mais desprotegidas frente a esse contexto (LOANGO y CARRASCAL, 2020).

Por exemplo, quando médicos franceses propõem experimentações em povos africanos para servirem como cobaias de fármacos e tratamentos em 
pleno 2020. Seguindo assim a máxima das economias políticas da doença frente as oportunidades que a precarização das vidas terceiro-mundistas oferece para as indústrias farmacêuticas do norte (SILVA, 2018). Não à toa o brasil é país predileto por empresas para testagem e experimentação terapêutica.

As situações de trabalhos informais, falta de saneamento básico, lastros escravocratas nas relações trabalhistas, extrema desigualdade, são vários os fatores que contribuem na composição desse cenário de pandemia racializada. Nosso primeiro óbito registrado do COVID 19 no país foi de dona Cleonice, uma senhora negra obrigada a continuar trabalhando como doméstica para patroa branca e rica que acabara de retornar contaminada de viagem ao exterior. De lá para cá, as coisas só pioraram. Vivemos tempos de suspensão dos dados oficiais das mortes pelo vírus, táticas estatais de controle das narrativas de informação, com avanço de expressões eugenistas e persecutória de políticos de extrema-direita, naturalizando e banalizando as políticas de ódio.

Somos a caricatura "mal diagramada" (Aza Njeri, 2019) de um ocidente nortecêntrico assassino e violento, forjado sob a guerra racial e exploratória da terra/natureza ancestral. Uma guerra de mais de 522 anos, tanto biológica, quanto material e também de ideias. Em que medida a educação, enquanto instituição formadora na sociedade, ao contribuir para a reprodução desses valores e imagens sócio raciais vigentes, causam sofrimentos e adoecimentos? Para essa pergunta, a noção de epistemicídio torna-se chave.

O extermínio dos saberes diferentes, não hegemônicos, o chamado epistemicídio advém justamente desse racismo estrutural que informa o saber científico hegemônico há séculos, marginalizando pessoas pretas e indígenas, negando seu lugar de produção de conhecimentos legítimos (CARNEIRO, 2005). Na escola isso se dá de inúmeras formas. Está presente na grade curricular euro centrada, no congelamento imagético e estereotipado de outras etnias, nos equívocos repassados (RIBEIRO, 2017).

Está no descumprimento sistemático das leis que trazem como obrigatório os estudos em todas as disciplinas sobre histórias, filosofias e culturas indígenas, africanas e afro-brasileiras. Está também na baixíssima representatividade em cargos de gestão de pessoas pretas e indígenas. Fala-se de democracia racial e se aplica o racismo real. Fala-se de origem do mundo e ela começa para muita gente até hoje nos gregos helênicos. Fala-se de África via estereótipo. Falar de saberes ancestrais e de mudança curricular é ser acusada de doutrinadora. Porque contar que o brasil foi descoberto e salvo pelos portugueses evoluídos espiritualmente não é nada doutrinador. É só a verdade? Ou é mais um migué normatizado nas epistemes hegemônicas?

O epistemicídio enraíza-se profundamente junto aos silenciamentos cotidianos frente às diversas violências sofridas por crianças e jovens na escola. Também está na banalização da linguagem racista, do racismo recreativo. Está 
na base da naturalizada subestimação da cognição de estudantes negras/negros. Já ouvi até que as cotas raciais só mostram que as pessoas negras são menos inteligentes. Essa é a linha de raciocínio medida pela régua colonial.

O epistemicídio também está no apagamento racial das estudantes chamadas de "morenas e mulatas" ou aos estudantes "mais escurinhos". Habita nas imagens/conceitos reproduzidos socialmente sobre o lugar da escola pública como um lugar de ausências, de incapacidades epistêmicas e existenciais, de pobreza criminalizada, de desestruturação e marginalização. Onde muitas vezes o ser 'negra' associa-se somente a imagem/conceito da escravidão, de sexualidade e de crime.

Isso faz parte do sistema racial estruturante e segue persistindo dada a centralidade do pensamento único, excludente, universal e supremacista branco. É importante destacar que:

a colonização teve um papel fundamental na imagem produzida dos sujeitos africanos, reservando a eles um local de desumanização o que caracteriza de forma equivocada a sua incapacidade de produzir consciência crítica, privilégio destinado apenas aos seres com potências humanas, ou seja, os homens brancos. (RIBEIRO, 2017, p.13).

Considerando que o "racismo não é apenas um legado histórico, é também um dispositivo presente em todas as instituições brasileiras" (MEDEIROS, 2019), nessa experiência de pandemia racializada, devemos, talvez mais do que nunca, aprender com as nossas histórias invisibilizadas para construir outros horizontes educacionais. Cuidar de nossas pessoas mais velhas, guardiãs das memórias e saberes, que se tornam alvo nessa guerra biológica moderna anti-ancestral. Cuidar para que essas narrativas excludentes e letais não tomem de assalto também os espaços virtuais, as atuais trincheiras de ideias do mundo digital, conectado, globalizado e ainda excludente.

Uma prática docente contra colonial perpassa necessariamente por autoatualização e formação continuada podendo, pois, pautar-se no fomento à autodeterminação, à autonomia, à propositividade crítica de si e das pessoas que nos compõem. E isso só é possível se soubermos as possibilidades plurais que existem em sermos. Se conhecermos as várias histórias, tecnologias e saberes ancestrais que são apropriados e apagados em nome de uma história única, linear, predatória e desumanizadora.

É importante buscarmos nos entender enquanto coletividade se quisermos um viver bem, uma vez que estamos adoecidos de biodiversidade (IBERÊ, 2020). Enquanto docentes, formadoras de subjetividades e 
consciências, em prol de uma descolonização na escola, é imprescindível nos colocarmos também enquanto eternas aprendizes na caminhada desse farto e nutritivo banquete de saberes contra-hegemônicos.

Argumenta-se assim acerca da importância da descolonização de consciências e subjetividades, como necessário exercício individual e coletivo. Também uma tarefa pedagógica, pois há poder no pensamento crítico, diverso, não balizado pelo extermínio do outro, mas pelo agregar das diferentes potências. Talvez a educação faça mais sentido nessa proposta de travessia, que busque compromisso e engajamento frente a esse papel de responsabilização com o outro e consigo mesmo.

Uma formação contra colonial pode promover mais espaços de escuta, de diálogos, de autoconhecimento, de sentir-se integrado a uma coletividade maior. O individualismo me parece ser uma performance esperada da naturalização violenta que o capitalismo produz de apartamento da pessoa de sua comunidade. Consequência histórica da imposição da propriedade privada e do desmantelamento do poder coletivo. Pensar que não aprendemos nada na escola referente aos movimentos quilombistas no brasil, por exemplo, diz muito sobre nossos profundos apagamentos e desmobilizações sociais. Afinal, falar de levantes e insurgências negras na história do capitalismo, que se estruturou sob acumulação de riquezas adquiridas por trabalho escravo 'é afronta para os senhores da história.

Construir uma subjetividade de caráter libertador é, pois, aprender junto as resistências históricas de intelectuais afrodiaspóricas (MUNANGA; GOMES, 2006). Pensar em lugares de cura é pensar também em quantos autoras e autores brasileiros não conhecemos em decorrência do racismo estrutural, pensadores que podem nos ajudar a compreender e a articular soluções para nossos desafios enquanto país. A teoria como um lugar de cura (hooks, 1994) caminha junto de uma educação como ética da liberdade, uma prática que busque transgredir a manutenção dos valores hegemônicos e construir reais comunidades de aprendizado. Em buscar 'transgredir' a estabilidade das opressões, é possível que se construa engajamento e solidariedade, onde sentimentos se transformem em ações que gerem saúde coletiva.

Pensar menos de forma profilática e mais em promover a saúde parece fazer mais sentido. Nessa entoada, junto aos movimentos da reforma sanitária no Brasil e das Conferências Internacionais em prol da ampliação do conceito de saúde, a promoção da saúde enquanto um novo paradigma para a saúde coletiva se destaca como reflexão. A promoção da saúde vem sendo balizada como um deslocamento do olhar biomédico de matriz individualista, da especialização, curativista, para um olhar intersetorial, com princípios de autonomia dos sujeitos e comunidades, reforçando o planejamento e o poder local (RABELLO, 2006). 
Joselita Rocha (2015) em pesquisa sobre como a coordenação pedagógica em uma escola pode servir como espaço de ressignificação do sofrimento docente, indagou sobre a importância de docentes criarem uma mobilização subjetiva coletiva (e individual) para evitar adoecer ao estabelecerem espaços de diálogos formativos. Colocando sua experiência, a autora afirma que com os "conhecimentos adquiridos por meio da bibliografia pude entender que a mobilização subjetiva e a alteridade é que dá esse equilíbrio para que o sofrimento não se transforme em doença". (ROCHA, 2015, p.11). Considero as palavras de Joselita muito expressivas. Somo às palavras de Joselita às de Audre lorde, trazidas por Shirley Tate (2018) quando diz que:

A dor é um evento, uma experiência que deve ser reconhecida, nomeada e em seguida usada de alguma forma para que a experiência mude e seja transformada em outra coisa: força, conhecimento ou ação. O sofrimento por outro lado, é o pesadelo revivido da dor não analisada e não metabolizada. (LORDE, 2007, p.172, apud TATE, 2018, p.197).

Pensar na importância de um ethos comunitário (MIRANDA, 2020) em contexto de pandemia radicalizada é talvez entender a luta por uma educação que não promova sofrimentos, através de posicionalidade nas ações balizadas pelo coletivo plural. É inspirar-se com mobilizações comunitárias presentes nas periferias e favelas brasileiras em prol de construção de saídas frente às violências institucionais. Buscar assumir a saúde de forma ampliada junto a mobilização consciente por condições equânimes de produção dessa saúde. Isso envolve justiça, memória, disputas, reparação, horizontalização de saberes, comunidade. "Quando, para encontrar uma solução nos voltamos para a comunidade maior, fica impossível o problema persistir" (SOMÉ, 2003, p. 121). Um caminho para pensar outros horizontes desde o chão da escola.

\section{Considerações Finais}

Este trabalho teve por objetivo refletir em que medida o enfrentamento ativo ao epistemicídio e ao racismo estrutural como horizontes na educação pública podem atuar como ações de promoção da saúde. Destaca-se que é impossível produzir política pública equânime, com justiça social, sem a perspectiva interseccional. Se não dimensionarmos que a própria categoria fundante de humanidade é balizada pelo crivo do branqueamento, é retórica de fachada, um possível migué, aqueles discursos institucionais de "diminuição" das desigualdades, mas nunca querendo acabar de vez com elas. 
O paradigma da interseccionalidade é de suma importância para desconstruir a pretensa neutralidade dos efeitos da COVID 19 (CAMPOALEGRE, p. 9, 2020). É também importante para destacar a conexão das lutas de nossas comunidades afrodiaspóricas e originárias. Dos locais aos globais, necessárias são as ações contra-coloniais. Tendo em vista a histórica colonização da educação formal, buscou-se argumentar a importância da prática docente posicionada para transformação via ação comunitária e pelo reconhecimento em sua dimensão ativa. Descolonizar as mentes para descolonizar também as práticas.

Pensar em fomentar ações de autonomia e organização das demandas locais requer também práxis na atuação docente que, cada vez mais, têm sido tensionadas nos processos de precarização e exploração do trabalho, com extensos registros de exaustão na docência adoecida. A escola, a educação enquanto tecnologias de 'transmissão' e format(ação) de uma agenda moderna/colonial, é um espaço estratégico de disputa por existências, estas múltiplas e potentes e que, no entanto, são furtadas de condições reais de existência plena nesse projeto de enrolação da modernidade.

Ancorada a proposta de olhar e aprender com o passado para possibilitar novos futuros e 'democratizar' o sonhar, espero que na ação comprometida com a coletividade, permitamos que crianças, jovens e adultas possam enxergar do presente um futuro em vida. Essa inspiração de ação coletiva tem como horizonte o ensinamento dos povos indígenas originários, quando afirmam que só sabem viver em liberdade (IBERE, 2020). O enfrentamento do vírus do COVID 19 segue em paralelo ao enfrentamento do pensamento que também mata, contamina e coloniza. E essa aversão à dominação e à opressão, segundo o professor Iberê (2020) é que o mantém viva as vidas originárias. Que possamos aprender.

\section{REFERÊNCIAS}

ASSUNÇÃO, Ada Ávila; OLIVEIRA, Dalila Andrade. Intensificação do trabalho e saúde dos professores. Educ. Soc., Campinas, v. 30, n. 107, p. 349-372, ago. 2009.

BANIWA, Gersem. José dos Santos Luciano. Antropologia indígena: o caminho da descolonização e da autonomia indígena. Trabalho apresentado na $26^{\mathrm{a}}$. Reunião Brasileira de Antropologia, realizada entre os dias 01 e 04 de junho de 2008, Porto Seguro, Bahia, Brasil.

BOTELHO, Denise; FLOR DO NASCIMENTO, Wanderson. COLONIALIDADE E EDUCAÇÃO: O CURRÍCULO DE FILOSOFIA BRASILEIRO ENTRE DISCURSOS COLONIAIS. Revista Sul-Americana de Filosofia e Educação (RESAFE), n. 14, p. 6689, 2011. 
BUSS, Paulo Marchiori. Promoção da saúde e qualidade de vida. Ciênc. saúde coletiva, Rio de Janeiro, v. 5, n. 1, p. 163-177, 2000.

BRASIL. Instituto Nacional de Estudos e Pesquisas Educacionais Anísio Teixeira. Relatório do 2 Ciclo de Monitoramento das Metas do Plano Nacional de Educação - 2018. 2. ed. - Brasília, DF: Inep, 2019.

BRASIL. Ministério da Saúde. Guia de implementação do quesito Raça/Cor/Etnia / Ministério da Saúde. Universidade de Brasília. - Brasília: Ministério da Saúde, 2018. $38 \mathrm{p}$.

CAMPOALEGRE, Rosa. [et al.] Más allá del decenio de los pueblos afrodescendientes. Editado por Rosa Campoalegre Septien ; Karina Andrea Bidaseca. - 1a ed. - Ciudad Autónoma de Buenos Aires: CLACSO, 2017.

CAMPOALEGRE, Rosa. COVID-19 Apuntes para un posicionamiento antirracista p.7-15 in: La pandemia racializada: debates desde la afroepistemología / Rosa Campoalegre Septien ... [et al.] ; coordinación general de Rosa Campoalegre Septien. - 1a ed.- Ciudad Autónoma de Buenos Aires: CLACSO, 2020.

CARDIM , Nathália ; ALCÂNTARA Manoela. Aula a distância para salvar o ano letivo no DF: solução ou migué. Jornal: Metrópoles. Publicado em 2020. Disponível em: https://www.metropoles.com/distrito-federal/educacao-df/aula-a-distancia-parasalvar-o-ano-letivo-no-df-solucao-ou-migue. Acesso em 05 mar 2020.

CARDOSO, Claudia Pons. Amefricanizando o feminismo: o pensamento de Lélia Gonzalez". Revista Estudos Fem. vol. 22 no. 3 Florianópolis Sept./Dec, 2014

CARLA, Maria. GDF QUER FAZER EAD COM 127 MIL ESTUDANTES SEM INTERNET E 8 MIL PROFESSORES SEM COMPUTADOR. Fonte: Sindicato dos Professores do DF-SINPRO. Publicado em 2020. Disponível em: https://www.sinprodf.org.br/gdf-quer-fazer-ead-com-127-mil-estudantes-sem-internet-e8-mil-professores-sem-computador/. Acesso em 04 junho 2020.

CARNEIRO, Aparecida Sueli. A construção do outro como não-ser como fundamento do ser. 2005. Universidade de São Paulo, São Paulo, 2005;

CARVALHO, Maria Regina Viveiros de. Perfil do professor da educação básica. Instituto Nacional de Estudos e Pesquisas Educacionais Anísio Teixeira. Série Documental. Relatos de Pesquisa. 67 p, 2018.

CONSAD, Conselho Nacional de Secretários de Estado da Administração PúblicaPesquisa apresentada pela Gerência de Epidemiologia e Estatística em Saúde da Secretaria de Estado de Administração Pública do Distrito Federal - ao Grupo de Trabalho em Saúde do Servidor (GTSS) 2014

CTC/PUC-RIO, Diferenças sociais: pretos e pardos morrem mais de COVID-19 do que brancos. 11ª Nota Técnica (NT) do Núcleo de Operações e Inteligência em Saúde (NOIS) do Departamento de Engenharia Industrial do Centro Técnico Científico da PUC-Rio (CTC/PUC-Rio), 27 maio de 2020.

FANON, Frantz. Pele negra, máscaras brancas. Bahia: Editora Edufba, 2008. 
FLAUZINA, Ana Luiza Pinheiro. Corpo negro caído no chão: o sistema penal e o projeto genocida do Estado brasileiro. Dissertação de mestrado submetida ao Programa de Pós-Graduação em Direito da Universidade de Brasília. Brasília: UnB, 2006.

FLORES, Tarsila. Genocídio da juventude negra no Brasil: as novas formas de guerra, raça e colonialidade do poder. In: MACEDO, A. et al. (Org.). Direitos humanos: diversas abordagens. Rio de Janeiro: Câmara Brasileira de Jovens Escritores, 2016. p. 109-125.

GOES, Emanuelle Freitas; RAMOS, Dandara de Oliveira; FERREIRA, Andrea Jacqueline Fortes. Desigualdades raciais em saúde e a pandemia da Covid19. Trab. educ. saúde, Rio de Janeiro, v. 18, n. 3, e00278110, 2020.

GOMES, Nilma Lino. O movimento negro educador. Saberes construídos nas lutas por emancipação. Petrópolis: Vozes, 2017.

GONZALEZ, Lélia. O papel da mulher negra na sociedade brasileira. In: Spring Symposium the Political Economy of the Black World, Los Angeles, 10-12 maio 1979c. (Mimeo.)

GONZALEZ, Lélia. “Nanny”. Humanidades, Brasília, v. 17, ano IV, p. 23-25

HARAWAY, Donna. Manifesto Ciborgue: Ciência, tecnologia e feminismo-socialista no final do século XX. In. Tadeu, T.(Org.) Antropologia do ciborgue: as vertigens do pós-humano. Belo Horizonte: Autêntica, 2009. Pp 33-118.

hooks, bell. Ensinando a transgredir: a educação como prática da liberdade. São Paulo Martins Fontes, 2019

IBERÊ, Daniel. Bem viver em 520 anos de Pandemia: resistência e experiências dos Povos originários. Debate no canal de youtube SEMACO_EnSIS, transmitido dia 05 de junho de 2020, disponível em:

$<$ https://www.youtube.com/watch?v=tKNfqxQNPtk>. Acesso no mesmo dia.

LOANGO, Anny. CARRASCAL, Airlin. La doble emergencia de las poblaciones afrodescendientes ante la crisis del COVID-19 p.22-29 In :La pandemia racializada : debates desde la afroepistemología / Rosa Campoalegre Septien ... [et al.] ; coordinación general de Rosa Campoalegre Septien. - 1a ed.- Ciudad Autónoma de Buenos Aires: CLACSO, 2020.

MEDEIROS, Deborah Prado. Sobre relações raciais e processos de subjetivação. Entrevista à Federação Psicanalítica da América Latina. Disponível em: <http://www.fepal.org/entrevista-a-deborah-medeiros/> Acesso em: 01 de mar 2020.

MEDEIROS, Danyela; CRUZ, Shirleide P. A Jornada de Trabalho no Distrito Federal como elemento condicionante para valorização do Trabalho Docente, Olhar de professor, Ponta Grossa, 20(1): 65-74, 2017.

MIRANDA, Cláudia. Poblaciones afrobrasileñas y COVID-19 Ethos comunitario y otras formas de lucha, p.15-22 in: La pandemia racializada : debates desde la afroepistemología / Rosa Campoalegre Septien ... [et al.] ; coordinación general de Rosa Campoalegre Septien. - 1a ed.- Ciudad Autónoma de Buenos Aires: CLACSO, 2020.

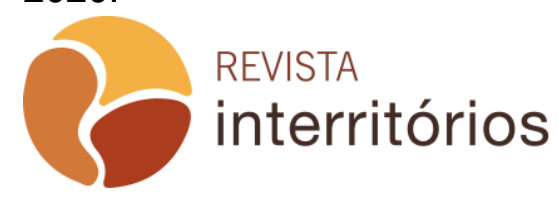


MUNANGA; Kabengele, GOMES; Nilma Lino. (2006). O negro no Brasil de hoje. São Paulo: Global. 2006. (Coleção para entender).

NASCIMENTO, Wanderson Flor do. Gramáticas morais, riscos mortais. Interface (Botucatu). 2019

NASCIMENTO, Abdias. O genocídio do negro brasileiro: processo de um racismo mascarado. Rio de Janeiro: Paz e Terra, 1978.

NJERI, A. Educação Afrocêntrica como via de luta antirracista e sobrevivência na Maafa. Revista Sul-Americana de Filosofia e Educação (RESAFE), n. 31, p. 4-17, 17 nov. 2019.

NOGUEIRA, Renato. Afrocentricidade e educação: os princípios gerais para um currículo afrocentrado. Revista Africa e Africanidades, Ano .3 -n.11, novembro, 2010.

PASSOS, Rachel; NOGUEIRA, Cláudia Mazzei. O fenômeno da terceirização e a divisão sociossexual e racial do trabalho. Rev. katálysis, Florianópolis, v. 21, n. 3, p. 484-503, dez. 2018.

PONTES, Katiúscia Ribeiro. Kemet, escolas e arcádeas: a importância da filosofia africana no combate ao racismo epistêmico e a lei 10639/03. [Dissertação de mestrado]. Rio de Janeiro: Centro Federal de Educação Tecnológica Celso Suckow da Fonseca, CEFET/RJ. 2017

RABELLO, Lucíola Santos. Promoção de saúde: desafio ou adaptação: a construção social do conceito, de Alma-Ata aos dias atuais, no Brasil e no Canadá. 2006. 193 f. Tese (Doutorado em Estudos Comparados sobre as Américas)Universidade de Brasília, Brasília, 2006.

ROCHA, Joselita Batista L. A COORDENAÇÃO PEDAGÓGICA COMO ESPAÇO POTENCIAL DE RESSIGNIFICAÇÃO DO ŞOFRIMENTO DOCENTE. [Monografia]. Brasília: Centro de Estudos Avançados Multidisciplinares, Universidade de Brasília/UNB, 2015.

SANTIAGO, Abinoan. Mesmo em crise, estados pagam acima do piso para professores; veja ranking. Publicado em 2019. Disponível em :

https://www.gazetadopovo.com.br/educacao/mesmo-em-crise-estados-pagam-acimado-piso-para-professores-veja-ranking/. Acesso em 10 fev 2020.

SANTOS Silvio Matheus Alves. O método da autoetnografia na pesquisa sociológica: atores, perspectivas e desafios. In: PLURAL, Revista do Programa de Pós-Graduação em Sociologia da USP, São Paulo, v.24.1, 2017, p.214-2412017; 28. Saúde Soc. São Paulo, v.25, n.3, p.535-549, 2016

SEDF, Secretaria de Educação do Distrito Federal. Nossa Rede. Servidores. Disponível em: http://www.se.df.gov.br/servidores-3/. Acesso em: 10 de mar 2020

SEDF, Secretaria de Educação do Distrito Federal. Mulheres representam $72 \%$ na SEEDF. Atualizado em 30/10/18, disponível em: http://www.se.df.gov.br/mulheresrepresentam-72-na-secretaria-de-educacao/. Acesso em: 10 de mar 2020 
SEPLAG, Secretaria de Estado de Planejamento, Orçamento e Gestão do Distrito Federal. Relatório de Inspeção na área de pessoal da Subsecretaria de Segurança e Saúde no Trabalho, Subcontroladoria de Controle Interno - SUBCI, 2이린

SILVA, Rosana Maria Nascimento Castro. Precariedades oportunas, terapias insulares: Economias politicas da doença e da saúde na experimentação terapêutica. Tese (Doutorado em Antropologia Social). Brasília: Universidade de Brasília, 2018.

SOMÉ, Sobonfu. $O$ espírito da intimidade: ensinamentos ancestrais africanos sobre maneiras de se relacionar. São Paulo: Odysseus, 2003;

SOUZA, Neusa Santos. Tornar-se negro. Rio de Janeiro: Graal, 1983

SOUZA, J. Racismo institucional e saúde da população negra. Revista

TATE, Shirley Anne. Descolonizando a raiva: a teoria feminista negra e a prática nas universidades do Reino Unido. In: BERNADINO-COSTA,J; MALDONADOTORRES, N; GROSFOGUEL, R.(Orgs.) . In: Decolonialidade e pensamento afrodiaspórico. Belo Horizonte: Autêntica Editora, 2019, p.183-201;

WERNECK, Jurema. Nossos passos vêm de longe! Movimentos de mulheres negras e estratégias políticas contra o sexismo e o racismo In: Vents d'Est, vents d'Ouest: Mouvements de femmes et féminismes anticoloniaux [en línea]. Genève: Graduate Institute Publications, 2009 